\title{
ÉKPHRASIS E AS FRONTEIRAS DA DESCRIÇÃO EM TÁCITO
}

\author{
FÁBIO FAVERSANI ${ }^{*}$ \\ Universidade Federal de Ouro Preto
}

\begin{abstract}
Resumo. Este artigo busca analisar dois episódios dos Anais, de Tácito, que permitem apontar para o afastamento entre o que era dado a ver e o que fato se passava nos ambientes aristocráticos no Principado romano. Essa tensão entre o que via/dizia e o que se fazia/pensava é fundamental para entender a ékphrasis na estratégia narrativa taciteana. Palavras-chave. Tácito; Anais; Britânico; Agripina; ékphrasis.
\end{abstract}

D.O.I. 10.11606/issn.2358-3150.v19i1p43-53

NeSTE TRABALHO PRETENDEMOS DISCUTIR, TENDO POR BASE DOIS EPISÓdios dos Anais, de Tácito, um aspecto específico relativo à produção dos textos históricos sob o Principado. Os episódios que colocaremos em evidência são aqueles dos assassinatos de Agripina e Britânico. O aspecto que queremos colocar em discussão é o compromisso que o autor deveria ter com a composição de uma narrativa que fosse verdadeira. Escrever uma narrativa verdadeira no Principado e sobre eventos do Principado se revelava algo especialmente difícil. Escrever uma narrativa verdadeira significava se colocar em confronto com os homens deste tempo, que eram viciosos e pouco dispostos a críticas. Tácito trata deste ponto no chamado segundo proêmio dos Anais. Diz Tácito que "mesmo que suas famílias estejam extintas (trata de seus personagens que viveram sob Tibério), haverá pessoas que acreditarão, pela semelhança de costumes, que o relato dos crimes cometidos por outros é uma imputação que é feita a si. Mesmo a glória e a virtude podem ofender, porquanto criam um contraste com o comportamento destes". ${ }^{1}$ Ainda que ele afirme tanto nos Anais quanto nas Histórias que poderia dizer a verdade, seguindo a famosa fórmula "sine ira et studio", 2 é obrigado

\footnotetext{
* Doutor em História Econômica pela Universidade de São Paulo (2001), com pós-doutorado pela University of Oxford (2003, 2012-2013). É um dos coordenadores do Laboratório de Estudos sobre o Império Romano (LEIR-UFOP).

** Artigo recebido em 05.ago.2015 e aceito para publicação em 31.out.2015.

${ }^{1}$ Tac., Ann. 4.33.4.

2 Tac., Ann. 1.1.3.
} 
a admitir os limites que encontrava para fazê-lo. Sendo assim, a possibilidade da narrativa histórica ser composta conforme a verdade estaria condicionada ao novo ambiente em que ela seria produzida. As disputas entre os aristocratas, no interior das quais se coloca a produção literária, teriam suas condições de realização dramaticamente modificadas com o Principado.

Ainda que eu, pessoalmente, tenda cada vez mais a perceber a necessidade de se matizar esta visão, sob a República, tem-se a imagem de um governo aristocrático, poliárquico. Os aristocratas disputavam posições no Estado. ${ }^{3}$ Iniciavam por aquelas posições mais modestas e, ao longo da vida poderiam ir avançando em uma disputa férrea com outros aristocratas, para atingir as posições mais elevadas, como o consulado, que era para poucos. Ronald Syme, em seu clássico The Roman revolution, afirma que: "em qualquer época da história da Roma Republicana, cerca de vinte ou trinta homens, provenientes de uma dúzia de famílias dominantes, detinham o monopólio das magistraturas mais importantes e do poder". ${ }^{4}$ Nesta disputa acirrada, tinha destaque a capacidade oratória dos aristocratas, que constituía uma das esferas de competição da elite. Era exigida dos aristocratas a exposição em diversas arenas públicas, especialmente nos tribunais, e na assembléia e, no caso daqueles que chegavam aos níveis mais elevados, no Senado. Este talento oratório não se mostrava apenas em ambiente público, mas também na esfera privada dos banquetes, espaço convivial onde a produção literária circulava. A oratória servia não só para que o aristocrata se destacasse entre seus pares, apresentando-se como homem elevado e capacitado. A oratória servia como arma de ataque e defesa na luta política. Compor ataques e se defender deles era fundamental para a construção de um cursus honorum elevado. Uma boa prova disto é César, que nos deixou seus de Bello Ciuili e de Bello Gallico, que nada mais são que uma ação política dirigida aos presentes e à posteridade. Além disso, o uso da oratória por um aristocrata era também meio para construir uma ampla clientela. Cabia a um grande aristocrata defender seus amigos nos tribunais e em outras arenas públicas. A leitura das obras de Cícero mostra bem como este foi um fator fundamental para sua carreira.

Esta competição crescente entre os aristocratas foi levada até a mais absoluta desmedida no século 1 a.C. Os aristocratas se colocaram à frente dos exércitos para sobrepujar seus adversários. Foram longos anos de guerras civis intercalados por breves intervalos de uma paz instável e talvez

\footnotetext{
${ }^{3}$ Afirmamos no Estado, mais do que no governo, uma vez que não se trata de um governo representativo e os aristocratas, ao serem eleitos, compunham posições de destaque no Estado, mais do que no governo.

${ }^{4}$ Syme 2002, 18.
} 
ainda mais sanguinária para a aristocracia do que a própria guerra, em razão da perseguição aos vencidos, em especial no contexto das proscrições. As guerras entre Mário e Sulla; César e Pompeu; Otaviano e Marco Antônio criaram as condições para a emergência de um novo regime: o Principado. Gerido em meio à forte insegurança das guerras civis, o Principado se impôs como realidade praticamente incontornável, conforme destaca Tácito tanto nos Anais quanto nas Histórias. ${ }^{5}$ A competição sem limites entre os aristocratas levaria à destruição do Império. Impunha-se a mediação de um Princeps que colocasse ordem a um mundo caótico e que tendia a sua autodestruição, à medida que concentra forças enormes, como jamais vistas. É o que lemos de forma muito clara em Sêneca, no seu De clementia.

Isto significava o fim das disputas sem freios entre os aristocratas. Em última instância, tudo seria decidido pelo Imperador. Seguindo esta lógica, requeria-se que o Imperador fosse o mais capacitado entre os aristocratas, o mais poderoso dentre eles, aquele que pode se colocar entre todos os demais e fazer cessar o conflito, a discórdia. Aquele que imponha que as disputas aristocráticas por honra, que seguiam, se dessem em paz. Isto coloca um paradoxo importante ao principado. Se o imperador é por definição o mais valoroso dos aristocratas, caso um aristocrata mostre valor invulgar e passe a ser reconhecido pelos demais, este aristocrata poderá facilmente ser tomado como alguém que aspira à posição imperial. Deste modo, tem-se um movimento duplo. Por um lado, os imperadores serão acusados de não reconhecer aristocratas valorosos, por temê-los. Por outro lado, os próprios aristocratas evitarão a exposição excessiva de seus talentos e evitarão um reconhecimento por demais ruidoso de seu valor. Isto é notável em Tácito, especialmente quando ele faz a biografia de Agrícola, seu sogro, ou quando apresenta o obituário de Petrônio e diz que este "entregue aos vícios, ou dedicando-se à imitação dos vícios, foi admitido entre os poucos familiares de Nero". ${ }^{\circ}$

Paralelamente à impossibilidade de se mostrar por demais valoroso, excelente, tinha-se também a impossibilidade de fazer críticas aos poderosos, que poderiam ser vistas como contestação ao próprio Imperador, ou mesmo de elogiar a virtude, como vimos Tácito afirmar. Não podendo tratar nem das virtudes nem dos vícios, cabia ao orador mostrar sua excelência tratando de tudo quanto estivesse apartado da realidade imediata, concentrando-se nos aspectos formais da composição do discurso. Teve-se assim o império das recitationes (e para alguns a decadência da oratória), tão debatidas hoje em dia. ${ }^{7}$

\footnotetext{
${ }^{5}$ E.g.: "Após a batalha de Ácio, quando pela paz todo poder foi conferido a um." Tac., Hist. 1.1.1.

${ }_{6}^{6}$ Tac., Ag. 16.18. 2.

${ }^{7}$ Para este tema, cf. Syme 2002.
} 
Neste contexto, sob o Principado, teríamos a chamada decadência da oratória não só pelo esvaziamento de esferas públicas antes importantes, mas também porque a competição entre os aristocratas perde o sentido que antes tinha. Isto se refletiu na educação, como mostram as onipresentes críticas dos contemporâneos, dentre as quais destacaríamos, a título de exemplo apenas, os cinco primeiros capítulos do Satyricon. Contudo, tendemos a concordar com Francesca Santoro L'Hoir quando ela nos lembra que "ainda que Quintiliano e outros, incluindo Tácito, queixem-se do declínio da eloqüência, tais lamentações, segundo a opinião dos estudos mais recentes, parece ser pouco mais do que tópica retórica do gênero "não-se-fazem-mais-as-coisas-como-se-faziam-antigamente". ${ }^{8}$ O que temos, a nosso ver, é o surgimento de uma série de novas fronteiras para a prática dos oradores, que não podiam ser elogiadas por um aristocrata. Assim, por exemplo, não se poderia fazer o elogio de um orador que fosse ambíguo, falasse sobre o que era central de forma indireta, tratando-o de forma oculta em meio a um tema central distante da realidade. Não se podia elogiar um orador que explicitamente abrisse mão se sua autonomia. Mas era este orador que era exigido. Como nos diz explicitamente Luciano de Samósata, em seu Como se deve escrever a história, o autor que quer elogiar um comandante militar, para não parecer adulador, não deve fazer o elogio. "Uma coisa desse tipo, se é que é assim, devia ser deixada para que nós pensássemos, em vez de ele próprio dizer" (17). ${ }^{9}$ Ou seja, de algum modo, teríamos dois historiadores aqui, aquele que escreve a história e os seus leitores/ouvintes.

Começa a se exigir uma dissociação entre o que se diz e o que se pensa. Tácito diz que ele teve o privilégio de poder dizer o que pensava, mas deixa claro que seria um momento excepcional. Em suas palavras: "um tempo como o nosso, em que é lícito sentir o que se quer e dizer o que se sente ${ }^{\prime \prime} .{ }^{10}$ Para identificar se o que é dito corresponde ou não ao que se pensa, exige-se um novo ouvinte/leitor. Este deve julgar o que é verdadeiro ou falso, o que é justo e merecido ou o que é adulatório e mentiroso, fruto de um officium que tenha o orador com os poderosos. Nada disso será dito claramente. A falsidade universal e os prejuízos que isto gera - até mesmo para o soberano - são mostrados deliciosamente, por exemplo, em Plutarco, em seu livrinho sobre Como distinguir o bajulador do amigo. Estes temas da dissimulação e da ambigüidade dos escritores do Principado estão no centro de alguns dos debates ainda atuais. Bem conhecida contribuição a este respeito é a obra de Shadi Bartsch, Actors in the audience: theatricality and doublespeak

${ }^{8}$ L'Hoir 2006, 251-2.

9 Tradução de Jacyntho Lins Brandão.

${ }^{10}$ Tac., Hist. 1.1.4. 
from Nero to Hadrian. ${ }^{11} \mathrm{O}$ exercício de desvendar o que está por trás do que foi dito, do que está oculto pelas palavras - como algo mais importante do que aquilo que as palavras dizem -, pode ser visto claramente nas tentativas que se dão ainda hoje de descobrir as farsas que foram ditas e quais as verdades que elas esconderiam, como nos casos dos elogios Valério Máximo a Tibério, de Lucano a Nero e aqueles de Quintiliano a Domiciano, ou mesmo de Tácito a Trajano, por que não? Outro exemplo da busca de revelar as farsas produzidas pela literatura do Principado está na divertida busca pela identificação de Trimalquião. Quantos personagens históricos não se quis associar ao famoso liberto? A verdade, assim, não estaria no texto, mas na imagem que o leitor poderia formar sobre o que não pode ser dito.

A primeira dificuldade de manter o compromisso com a verdade neste novo ambiente estaria em construir a narrativa. Haveria estímulos muito fortes para agir conforme motivações de momento. Os aristocratas, especialmente os imperadores, quando têm poder, recebem elogios imerecidos dos aduladores. Quando perdem o poder, recebem críticas exageradas. Todas as narrativas seriam falsas..$^{12}$ Isto nos leva ao segundo aspecto que pretendemos destacar. As narrativas falsas são compostas por aristocratas que visam a interferir nas disputas em torno do poder quer buscando ser favorecidos quer procurando prejudicar a outros aristocratas, especialmente os imperadores que já haviam falecido. ${ }^{13}$

Os historiadores eram aristocratas envolvidos em disputas pelo poder e devem ser vistos como tais, compreendendo-se sua própria obra como ação política de um aristocrata e não como mera e descompromissada atividade literária. ${ }^{14} \mathrm{~A}$ escrita da história era uma ação política, como deixa claro, para citar um exemplo, Plínio, o Jovem em carta a Titinius Capito: “Persuades-me a escrever uma história e não persuades-me sozinho. (...) Parece-me particularmente belo que alguém não deixe morrer os que merecem a eternidade e que, com a fama dos outros, aumente a sua". ${ }^{15}$

No entanto, como deixa claro Tácito, não há muitos exemplos elevados para destacar. Pelo contrário, predominam as baixezas. Diz Tácito: "Ninguém compararia nossos Anais com os escritos dos que compuseram a história antiga do povo romano" (...) "Nosso trabalho dispõe de espaço

\footnotetext{
${ }^{11}$ Bartsch 1994.

${ }_{12}$ Como diz Tácito em Hist. 1.1. 2: "Ao mesmo tempo, a verdade foi afetada de diversas maneiras".

${ }^{13}$ É o que afirma Tácito na continuação da passagem citada anteriormente: "Primeiro pela ignorância das coisas públicas e das outras, depois em razão de suas vontades ou por sua vez movidos pelo ódio contra os dominantes".

${ }^{14}$ Cf. Sailor 2008, especialmente a segunda seção do primeiro capítulo, pp. 10-35.

${ }^{15}$ Plin., Ep. 5.8.1.
} 
estreito e inglório"1. ${ }^{16}$ Claro que se pode ler esta passagem do chamado segundo proêmio como um exercício retórico conhecido, de rebaixar-se para que o público elevasse a obra e seu autor, a captatio beneuolentiae. Muito bem que seja, mas resta ainda claro que se trata de uma "nouvelle histoire" a de Tácito. Uma história que sendo feita em um tempo diverso, estudando um tipo de passado diferente, apontará para outra utilidade. Assim, lemos em Tácito, ainda em registro comparativo: "Com efeito, o estado das nações, as peripécias dos combates, as mortes célebres dos chefes retêm e reavivam a atenção do leitor [e estes eram os objetos dos historiadores de antes]; nós [tratamos de] ordens cruéis, acusações contínuas, amizades enganosas, ruína de inocentes e sempre as mesmas causas de morte atrelamos umas às outras, apresentando fatos semelhantes e tediosos ${ }^{\prime 17}$ Neste novo ambiente não se pode dizer o que é justo sem o risco de perder a vida. Para citar um exemplo dado por Tácito, lembramos que foi isto o que aconteceu com Cremutius Cordo, perseguido por Tibério por causa de sua obra. ${ }^{18}$ Impor-se-ia falar a verdade por uma nova maneira, talvez.

Tácito, no entanto, tem sido visto ao longo do tempo predominantemente como um campeão contra os tiranos, um crítico dos maus imperadores. Como exemplo disto, podemos citar a tradução de Liberato de Carvalho, feita na primeira metade do século 19 e que circula ainda amplamente nos meios acadêmicos brasileiros através da edição dos Clássicos Jackson. Esta tradução é toda calcada neste entendimento. Trata-se de uma tradução feita há quase duzentos anos, explicitamente como a ação de um aristocrata contra a tirania que o colocou na prisão e o enviou para o exílio. Foi preso em Portugal e depois exilado na Inglaterra que Liberato de Carvalho traduziu os Anais. A noção de que os reis tiranos, malévolos, colocavam os aristocratas virtuosos silenciados - e os aristocratas viciosos em evidência - mantém uma longa predominância. Esta visão acaba por dar destaque ao papel desempenhado pelo imperador e colocar em papel secundário os aristocratas. Mas se a obra de Tácito pode ser vista como uma crítica aos tiranos, talvez também possa ser vista como um conjunto de lições dirigidas aos aristocratas sobre como sobreviver aos tiranos. O conselho que predomina em Tácito, a nosso ver, é que os aristocratas deveriam sempre dissimular, criando uma falsa imagem do que se pensa ou do que se faz. Assim, a primeira virtude exigida de um aristocrata seria saber mentir.

Isto nos conduz, então ao segundo aspecto que pretendemos destacar. As narrativas, para serem verdadeiras, não deveriam narrar o que foi

\footnotetext{
${ }^{16}$ Tac., Ann. 4.32.1-2.

17 Tac., Ann. 4.33.3.

${ }^{18}$ Cf. Tac., Ann. 4.34-5, ou seja imediatamente após o segundo proêmio.
} 
dito ou o que se fez, porquanto os aristocratas usualmente não diriam o que pensavam e não agiriam de modo a que se percebessem seus interesses. Como já citamos, lembra-nos Tácito que apenas raramente seria "lícito sentir o que se quer e dizer o que se sente ${ }^{\prime \prime} .{ }^{19}$ Compor a narrativa histórica, assim, exigiria que se dissesse a verdade não dita, que se revelasse a ação que poderia vir a ser empreendida por trás de uma outra que aparentemente indicaria para outro caminho. O relato verdadeiro, assim, não descreveria o que foi feito ou foi dito. Afinal, o que foi feito e dito são mentiras. O relato verdadeiro diria o que não foi dito e o significado oculto do que foi feito, que invariavelmente é diverso do seu significado mais explícito e óbvio.

Assim, quando Nero decide matar Agripina passa a dirigir-lhe palavras doces e dedicar a ela atenção de filho devotado. Agripina, usualmente habilidosa em traduzir os sentidos ocultos do que se diz e o que se faz, não soube ler a falsidade de seu filho em um primeiro momento. Tácito atribui isto à condição feminina de Agripina. Em suas palavras, ela foi enganada graças à "facilidade que as mulheres têm para acreditar em boas notícias". ${ }^{20}$ Em meio a tanta falsidade, Tácito em vários momentos vacila na construção da descrição. À despedida, por exemplo, a imagem criada é clara, mas a verdade que ela encerra é impossível de discernir. Diz Tácito: “Ele a conduziu e a abraçou bastante longamente, beijou-a nos olhos e no peito, seja para dissimular, seja porque a última visão da mãe que iria morrer tocou seu espírito, por brutal que fosse". ${ }^{21} \mathrm{O}$ que se segue, como sabem, é uma comédia de erros. O plano de fazer o assassinato parecer um acidente, resultado de um naufrágio fracassa. O navio a lança ao mar, mas ela não se afoga. Acerronia, que a acompanhava e vai ao mar também, quis passar por ela para ser salva, mas é morta a golpes de instrumentos navais pelos marinheiros. Agripina finge não ser Agripina e sobrevive, nadando por si só. A vítima, sabendo-se objeto de uma conspiração, tudo faz para que não saibam que ela percebeu que a tentavam matar. Manda assim um emissário para o mandante de seu assassinato, seu filho, para que diga a ele que sua mãe sobreviveu ao terrível "acidente", que ele não se preocupasse. Nero, notando que a mãe não o acusa, tem a certeza de que ela se prepara para a vingança do crime que tentara cometer. Então, é encenada mais uma farsa. O enviado de Agripina é acusado de tentar matar o imperador. Coloca-se um instrumento perfurante em suas mãos e ele é morto, como homicida. Agripina, falsamente acusada de tentar matar seu filho, será então assassinada - de verdade.

\footnotetext{
${ }^{19}$ Tac., Hist. 1.1.4.

${ }^{20}$ Tac., Ann. 14.4.1.

${ }^{21}$ Tac., Ann. 14.4.4.
} 
Esta sequência de mentiras leva à justificativa para a morte de Agripina. No final, o Senado rendeu graças aos deuses pela salvação do imperador. Mais uma vez, a mentira se fez verdade. Para tanto, primeiro os soldados, estimulados por Burro, felicitam Nero que se via atormentado pelo seu crime, depois os amigos rendem graças aos deuses nos templos, a seguir, os munícipes da Campânia. Por fim, ainda que tudo que se via indicasse um matricídio, todos se regozijavam com o fim de uma conspiração que nunca existiu. O Senado, ao final e mais que todos, desdobra-se em homenagens ao assassino e na execração da vítima. Tudo que se vê, então, é incerto. Mesmo os prodígios já não indicam o que se vê. Apesar de numerosos sinais dos deuses em contrário, Tácito constata que Nero continuaria governando e cometendo crimes. ${ }^{22}$

Uma das principais virtudes da écfrase, como sabemos, é a clareza (saphanéia), necessária para que a elocução produza a visão do que se descreve por meio da audição. Mas como fazer ver o que não era visível? O que fazer quando o que é visível não revela uma realidade? Como fazer ver o que se oculta? Não se trata de descrever uma batalha noturna, como fez Tucídides. ${ }^{23}$ Todos tudo ocultam. Mas o Principado não é uma noite perpétua. Estes mesmo que tudo ocultam também a todo tempo se mostram, se expõem e até mesmo "espetacularizam" sua existência. Como nos diz Sêneca, por exemplo: "aqueles a quem o vulgo chama felizes exibem uma boa disposição fingida, carregada, contaminada de tristeza, e tanto mais lamentável quanto, muitas vezes, nem sequer podem se mostrar abertamente infelizes, antes se veem forçados, entre desgostos que lhes roem o coração, a representar a comédia da felicidade!" ${ }^{24}$

Assim, o desafio que chamaríamos de republicano de mostrar o que era visível e deve se manter como tal através da narração para que não se torne esquecimento é uma coisa. Trata-se de descrever uma ação. Outra coisa e desafio distinto é fazer ver o que não era visível, por que se ocultava na noite das virtudes. Neste caso, é preciso descrever uma ação e um ambiente, como foi o caso de Tucídides. Mas com o principado se cria uma nova fronteira, bastante interessante para a écfrase. Trata-se de descrever a ação que se vê e a ação que se pretende ocultar pela ação que é mostrada. $\mathrm{O}$ que se vê, é a mentira. O que se oculta, a verdade. A narrativa tem que operar com estes dois planos, que se explicam um ao outro, como a noite e a confusão dos combatentes em Tucícides. A ação dissimuladora é como o

\footnotetext{
22 Tac., Ann. 14. 7-12. 2.

${ }^{23}$ Th. 7.44 .

${ }^{24}$ Sen., Ep. 80.6.
} 
ambiente. ${ }^{25}$ Um exemplo notável deste procedimento nos parece poder ser encontrado na narrativa do assassinato de Britânico. Vejamos o episódio:

Nero se via cada vez ameaçado por seu irmão por adoção. Ele estava mais próximo de assumir funções públicas, uma vez que alcançava a idade competente para isto. Além disto, ele mostrava em todas as ocasiões que não era desprovido de talentos, vivacidade e ambição. Para piorar, Britânico era sempre colocado como uma ameaça contra Nero por sua mãe, Agripina. Quando contrariada, Agripina lembrou a Nero que do mesmo que lhe havia conduzido ao poder, tranquilamente faria o mesmo com o filho biológico de Cláudio. Nero decide então suprimir esta ameaça. A descrição do assassinato prima pela irrealidade. Em primeiro lugar, Tácito afirma que era costume que os mais jovens comessem em uma mesa em separado, uma alimentação mais frugal do que aquela dos mais velhos. Mas o relato torna o que é distante, próximo e visível. Britânico é morto por veneno, que não é colocado na bebida que seria experimentada, mas na água fria que foi usada para esfriar a bebida que estaria quente demais. Mais uma vez e sempre, o que se vê é ilusório. Cometido um assassinato à frente de todos, o que fazer? Tácito relata as reações. Os imprudentes fogem aterrorizados. Mas aqueles que eram mais inteligentes (altior intellectus) ficam em seus lugares e firmam os olhos em Nero. Tácito utiliza o adjetivo defixius para qualificar o olhar daqueles que ali se mantiveram. Como sói acontecer em Tácito, as palavras utilizadas podem gerar mais de um curso de leitura. A narrativa que se colocava em um plano geral, que permitia ver a mesa dos adultos e dos jovens, que divide o público que assiste a cena em dois grupos de anônimos, os imprudentes e os mais inteligentes, passa a dar um zoom em personagens. Primeiro em Nero, que finge que nada demais está acontecendo. Afirma que deve ser apenas um ataque

\footnotetext{
${ }^{25}$ Cremos importante ressaltar que, a nosso juízo, isto não pode ser dito para todos os autores imperiais. Ainda que seja um problema para a historiografia produzida no império, o desafio desta nova fronteira foi enfrentado de forma diversa pelos autores. No caso de Flávio Josefo, a écfrase obedece a outro propósito. Concordamos com Pere Villalba I Varneda quando afirma que para Josefo a "écfrase tem a missão de educar, de enriquecer com conhecimento o assunto histórico e de colocar um ritmo na narrativa historiográfica" (Villalba I Varneda 1986, 169). Assim, ainda que a narrativa de Josefo pudesse ser pensada em muitos momentos como eivada de "doublespeak", no sentido de Shadi Bartsch, o mesmo não pode ser dito para a écfrase neste autor. O uso da écfrase por este autor pode ser associada a uma estratégia de dar a máxima clareza a sua narrativa - e assim se separar da história feita pelos "gregos". Enquanto a história antiga dos judeus estava ao abrigo de toda polêmica e discussão porque tinha sido escrita por Deus e estava na Torá, aquela dos gregos era incerta porque sempre disputada. Diz ele sobre os gregos: "referem-se uns aos outros em seus livros e não hesitam em dizer o mais contraditório sobre as mesmas coisas" (J., Ap. 3,15). Neste sentido, Josefo declara ser esta história mais próxima daquela dos egípcios, onde encontra muitas coincidências com o saber que ele mesmo tinha. Neste sentido, afirma Josefo nas Antiguidades Judaicas: "tanto os nossos livros quanto os livros dos egípcios concordam sobre muitas coisas". (J. AJ. 8.159)
} 
de epilepsia, que o jovem logo retornará a si. Depois o foco se volta para Agripina, que mostra imenso pavor. Ainda que tente reprimir qualquer expressão, mostra-se comovida. Percebe que aquele assassinato indicava um grave risco para ela. Otávia, esposa de Nero e irmã do jovem que tinha acabado de ser assassinado, apesar de muito jovem, na avaliação de Tácito, agiu exemplarmente. Escondeu a dor, a estima, todos os seus sentimentos. O relato do episódio se encerra com Tácito levando o foco narrativo uma vez mais para o plano aberto. Diz ele: "Assim, após um breve silêncio, retoma-se a alegria dos convivas". ${ }^{26}$

Deste modo, podemos concluir que no Principado, na visão de Tácito, o que se vê não é real, pois todos precisam fingir se querem sobreviver. Por esta razão, desloca-se a fronteira da écfrase. Não se deve trazer diante dos olhos através da elocução o que foram os lugares, as ações, como ensinam os manuais de retórica. $O$ desafio é trazer frente aos olhos o que não podia ser visto, o que se ocultava. Assim, a descrição é uma sobreposição de visões possíveis e incertas. Cabe ao ouvinte treinar sua capacidade de ver muitas cenas onde existe uma. Entre a cena que se vê e as muitas que se ocultam, cabe a quem vê não simplesmente ver, mas também compor a cena. O Principado não admite testemunhas inocentes de seus acontecimentos. Ao que parece, a história do Principado também não se limita mais à simples descrição. Cabe ao leitor a indiscrição de ver o que a narrativa não pode colocar diante dos olhos. A pergunta que fica como conclusão é: uma narrativa assim complexa poderá ser dita decadente como nos apresentam a oratória sob o Principado?

\section{REFERÊNCIAS}

Bartsch, S. 1994. Actors in the audience: theatricality and doublespeak from Nero to Hadrian Massachusetts. Harvard University Press.

L'Hoir, F. S. 2006. Tragedy, rhetoric, and the historiography of Tacitus' Annales. Ann Harbor: The University of Michigan Press.

Sailor, D. 2008. Writing and empire in Tacitus. Cambridge: Cambridge University Press. Syme, R. 2002. Roman Revolution. Oxford: Oxford University Press.

Villalba I Varneda, P. 1986. The historical method of Flavius Josephus. Leiden: Brill. 
Title. Ekhphrasis and the boundaries of description in Tacitus.

Abstract. This paper aims to analyse two episodes of the Tacitus' Annals that allow us to point out the distance between what was given to see and what actually happened in aristocratic environments in the Roman Principate. This tension between what one saw/said and what happened/was thought is fundamental for our understanding of ekhphrasis in the Tacitean narrative technique.

Keywords. Tacitus; Annals; Britannicus; Agrippina; ekphrasis. 